www.mdpi.com/journal/molecules

Correction

\title{
Publisher's Note - Pagination Error, Molecules 2009, 14(3)
}

\section{Shu-Kun Lin}

Molecular Diversity Preservation International (MDPI), Kandererstrasse 25, CH-4057 Basel, Switzerland; E-mail: lin@mdpi.org

Published: 10 September 2009

Publisher's Note added on 10 September 2009: There is a pagination error in Molecules 2009, 14(3) with pages 1134-1144 missing. Thus, pages 1134-1144 are taken as a blank pages.

(C) 2009 by the authors; licensee Molecular Diversity Preservation International, Basel, Switzerland. This article is an open-access article distributed under the terms and conditions of the Creative Commons Attribution license (http://creativecommons.org/licenses/by/3.0/). 
Molecules 2009, 14

1135 
Molecules 2009, 14

1136 
Molecules 2009, 14 
Molecules 2009, 14

1138 
Molecules 2009, 14 
Molecules 2009, 14 
Molecules 2009, 14 
Molecules 2009, 14 
Molecules 2009, 14 
Molecules 2009, 14 